\title{
A novel analysis strategy for integrating methylation and expression data reveals core pathways for thyroid cancer aetiology
}

\author{
Bugra Ozer ${ }^{1,2 *}$, Osman Uğur Sezerman ${ }^{3}$
}

From Joint 26th Genome Informatics Workshop and Asia Pacific Bioinformatics Network (APBioNet) 14th International Conference on Bioinformatics (GIW/InCoB2015)

Tokyo, Japan. 9-11 September 2015

\begin{abstract}
Background: Recently, a wide range of diseases have been associated with changes in DNA methylation levels, which play a vital role in gene expression regulation. With ongoing developments in technology, attempts to understand disease mechanism have benefited greatly from epigenetics and transcriptomics studies. In this work, we have used expression and methylation data of thyroid carcinoma as a case study and explored how to optimally incorporate expression and methylation information into the disease study when both data are available. Moreover, we have also investigated whether there are important post-translational modifiers which could drive critical insights on thyroid cancer genetics.

Results: In this study, we have conducted a threshold analysis for varying methylation levels to identify whether setting a methylation level threshold increases the performance of functional enrichment. Moreover, in order to decide on best-performing analysis strategy, we have performed data integration analysis including comparison of 10 different analysis strategies. As a result, combining methylation with expression and using genes with more than 15\% methylation change led to optimal detection rate of thyroid-cancer associated pathways in top 20 functional enrichment results. Furthermore, pooling the data from different experiments increased analysis confidence by improving the data range. Consequently, we have identified 207 transcription factors and 245 posttranslational modifiers with more than 15\% methylation change which may be important in understanding underlying mechanisms of thyroid cancer.
\end{abstract}

Conclusion: While only expression or only methylation information would not reveal both primary and secondary mechanisms involved in disease state, combining expression and methylation led to a better detection of thyroid cancer-related genes and pathways that are found in the recent literature. Moreover, focusing on genes that have certain level of methylation change improved the functional enrichment results, revealing the core pathways involved in disease development such as; endocytosis, apoptosis, glutamatergic synapse, MAPK, ErbB, TGF-beta and Toll-like receptor pathways. Overall, in addition to novel analysis framework, our study reveals important thyroidcancer related mechanisms, secondary molecular alterations and contributes to better knowledge of thyroid cancer aetiology.

\footnotetext{
* Correspondence: bugraozer@sabanciuniv.edu

${ }^{1}$ Biological Sciences and Bioengineering Program, Faculty of Engineering and

Natural Sciences, Sabanci University, Istanbul, Turkey

Full list of author information is available at the end of the article
}

C 2015 Ozer and Sezerman This is an Open Access article distributed under the terms of the Creative Commons Attribution License (http://creativecommons.org/licenses/by/4.0), which permits unrestricted use, distribution, and reproduction in any medium, provided the original work is properly cited. The Creative Commons Public Domain Dedication waiver (http://creativecommons.org/ publicdomain/zero/1.0/) applies to the data made available in this article, unless otherwise stated. 


\section{Introduction}

Most common endocrine cancer observed in follicular cells is the Human Papillary Thyroid Cancer. It has highest incident rate among endocrine cancers, and it occurs in all age groups from children to older adults.

Biology of thyroid cancer includes both genetic and epigenetic alterations as driving forces of the disease state [1]. In literature, certain precursor genes have been associated with Human Thyroid Cancer. RAS gene mutations have been detected in 5-20\% and BRAF gene mutations have been reported in $28-69 \%$ of papillary thyroid cancer cases [2,3]. Variations in RET gene have also been frequently observed in papillary thyroid cancer cases $[4,5]$. Additionally, there are several genes reported in the work of Cancer Genome Atlas Research for Papillary Thyroid Carcinoma such as; PPARG, ALK, NTRK3 [6].

In addition to the studies on investigating genetic reasons behind thyroid cancer, various studies have been conducted to understand epigenetic alterations in thyroid cancer. In papillary thyroid cancer, numerous methylation studies have revealed that $R A R B$ (Retionoic Acid Receptor), CDKN2A (Cyclin-Dependent Kinase Inhibitor 2A), TSHR (Thyroid Stimulating Hormone Receptor), CDH1 (Cadherin 1, type 1), DAPK (DeathAssociated Protein Kinase 1), MLH1 (mutL Homolog 1) and RASSF1A(Ras associated gene) are observed to have significantly altered methylation levels $[7,8]$. Specifically RAS-MAPK signal activation via RASSF1A methylation has been detected in $20 \%$ of papillary thyroid cancer cases [9]. Additionally, tumour suppressors and oncogenes such as KISS1R, ADAMTS5, HOXB4, TCL1B, NOTCH4, TIMP3 can also be added to previous gene list of differentially methylated genes that have been observed in various disease conditions [10].

Besides individual genes, some signalling pathways are also reported to be affected with thyroid cancer such as; MAPK Signalling Pathway, the Natural Killer Cell pathway, The HIF1 $\alpha$ pathway and Thyroid-stimulating hormone receptor pathway [1]. Additionally, Toll-like receptor signalling pathway [11], Pentose-phosphate pathway [12] and ErbB pathway (Mtor pathway) have previously been linked with thyroid cancer [7]. Other pathways such as; TGF-beta signalling pathway [13], VEGF signalling pathway [14], Neurotrophin signalling pathway [15], Focal adhesion [16], Extracellular matrix activity [17], Adherens junction [18], p53 signalling pathway [19], Notch signalling pathway [20] are described as being active at thyroid cancer pathogenesis. Also observed at other cancer types, Apoptosis, Fc epsilon RI signalling pathway, Leukocyte transendothelial migration, $T$ cell receptor signalling pathway, B cell receptor signalling pathway, GnRH signalling pathway and Transcriptional misregulation in cancer are shown as being involved in thyroid cancer as well [21-23]. Overall, even though there are several reported genes and pathways that are linked with thyroid cancer, mechanisms employed in the disease development still remain unclear.

In recent decades, the nature of DNA methylation became a hot research topic with ongoing developments in technology. There are concrete evidences about epigenetics that, it plays a crucial role in disease development, especially in cancer [24-26]. From this perspective, incorporating epigenetic information into disease identification studies would shed light on the disease aetiology, thus improving the treatment procedure. For this purpose, a highly preferred way is to conduct both expression and methylation experiments. However, integrating methylation and expression data is a problem that is commonly confronted due to the complex relationship between methylation and expression. Recent studies show that searching for correlation between methylation and expression data is the most adopted strategy on tackling this problem. In this type of analysis, statistical analysis of both methylation and expression data are conducted separately and at the final stage, these results are compared with each other [27-32]. Another approach is to merge methylation and expression data prior to any kind of analysis by implementing general data integration algorithms [33,34]. Although general data integration algorithms enable merging of multi-layered data in an efficient way, they do not yield optimal results as they omit the nature of biological relationship between methylation and expression.

Methylation is a way to regulate the gene expression level mediated by environmental factors as well as posttranslational modifications and noncoding RNAs [35].The biological relation between methylation and gene expression is believed to be so that, for most of the genes, methylation has crucial role in repressing gene expression by blocking the promoters at which transcription factors can bind and initiate the expression process. Thus, it is expected to observe an inverse correlation between expression and methylation. However, there are also other works showing that there is not always inverse correlation between methylation and expression, hence transcription is defined as being independent of methylation for some of the genes [36].

Experimental results show that a change in methylation level does not always lead to a corresponding change in expression level due to variety of factors. At this point, the definition of a certain threshold considering the high correlation between methylation and expression may be beneficial when both methylation and expression data are available. In microarray expression experiments, a simple fold change of 2 is recommended between two conditions to obtain more reliable results. In methylation experiments, Beta-value $(\beta)$ is defined as the ratio of methylated 
probe intensity over the overall intensity composed of methylated and unmethylated probes. However, delta beta $(\Delta \beta)$ threshold is not well defined in the publications. The question "whether methylation significance values always correspond to significant alteration in methylation level", remains unanswered. In this sense, B-Value threshold in methylation experiments is an issue that needs to be seriously addressed; hence setting a valid threshold for methylation change between two conditions may be helpful in obtaining more accurate list of significantly methylated or unmethylated genes.

In this study, we have investigated how to obtain optimal results when both expression and methylation information are available and we have tried to understand the interplay between methylation and expression in thyroid cancer. For this purpose, our research focused on two main topics; whether setting a methylation level threshold improves the outcome of the analysis and how to obtain optimal results when expression and methylation information are both available. In this sense, we have conducted a threshold analysis for varying methylation levels considering the inverse correlation between methylation and expression. Similarly, in order to further understand whether using expression or methylation reveals more information about disease aetiology, we have made comparisons between 4 different datasets and 10 different analysis strategies. To support our findings and to show generalizability, we have also applied our framework to independent thyroid cancer dataset. Overall, in addition to a novel analysis framework, our study reveals potentially important thyroid-cancer related mechanisms and secondary molecular alterations which can contribute to better understanding of thyroid cancer aetiology.

\section{Methods}

\section{Dataset}

Dataset consisting of 8 normal and 10 tumour samples are obtained from Batch 230 and dataset consisting of 6 normal and 6 tumour samples are obtained from Batch250 Thyroid Cancer Carcinoma data in The Cancer Genome Atlas (TCGA) [6]. This dataset was used as a case study and training dataset. Additionally, we have also downloaded another 30 samples from the same source to test our findings on another independent dataset. In TCGA, while selecting normal tissue samples we have focused on including samples which are "matched" to the anatomic site of tumour. In correlation, while selecting tumour samples we have carefully chosen samples which have "matched" normal samples included in the same experiment.

We have only selected the samples that contain both RNA sequencing and methylation data at our study. According to data providers, all methylation data was obtained from Illumina Human Methylation 450k Chip, whereas all RNA sequencing data was obtained from
Illumina HiSeq machine. Data consisting of intensity values corresponding to each region for methylation chip and counting values corresponding to each gene for RNA-Seq are downloaded for our study.

For both methylation and RNA sequencing (RNA-Seq) experiments, statistical analyses are conducted for each batch independently and also by pooling both batches together before pre-processing the data.

\section{Methylation analysis}

Methylation is not a gene-specific but a region-specific phenomenon. Methylation occurring at different gene regions may end up having different outcomes. In our methylation analysis, we have investigated methylations occurring in first exon, 3'UTR, 5'UTR, gene body, intergenic region and transcription start sites using ChAMP package [37] which is available in R. ChAMP pipeline is specifically designed for analysis of Illumina HumanMethylation450k chip and it involves a sliding window approach (Probe Lasso) for annotating CpG regions with genomic locations [38].

In array-based methylation experiments, both Betavalue and $M$-value statistics are used as metrics to measure methylation levels. Beta-Value in methylation experiments is the estimate of methylation level using the ratio of the methylation probe intensity and the overall intensity whereas $\mathrm{M}$-value is a logit transformation of Beta-Value. For easier functional interpretation of the results, we have used Beta-Value at our analysis, which provides more intuitive biological interpretation as it roughly corresponds to the percentage of a methylation on a specific site [39].

After obtaining intensity data from TCGA, intra-array normalization is done using BMIQ normalization method [40] to avoid the bias introduced by the Infinium type 2 probe design. In order to assess the similarity of normalized methylation samples in both batches and the pooled data, multidimensional scaling plots based on top 1000 most variable probes and corresponding hierarchical clustering plots are shown in Figures 1 and 2. When looked at the MDS and clustering plots, not all tumour samples were clustered together and specifically in Batch230, control samples were in separate clusters. In order to validate the problem, we have conducted the same analysis three times by double-checking the parameters. Overall, the picture was better for the pooled dataset, where there were precise "control" clusters in the plot. Adding that TCGA is a well-designed database, we had doubts on excluding the outlying samples and thus, we have continued our analysis without any elimination but focusing on pooled dataset. The reason behind enhanced performance of pooled data against individual batch data may be due to the fact that pooled data increases the confidence rate 
Multidimensional scaling plots of methylation data

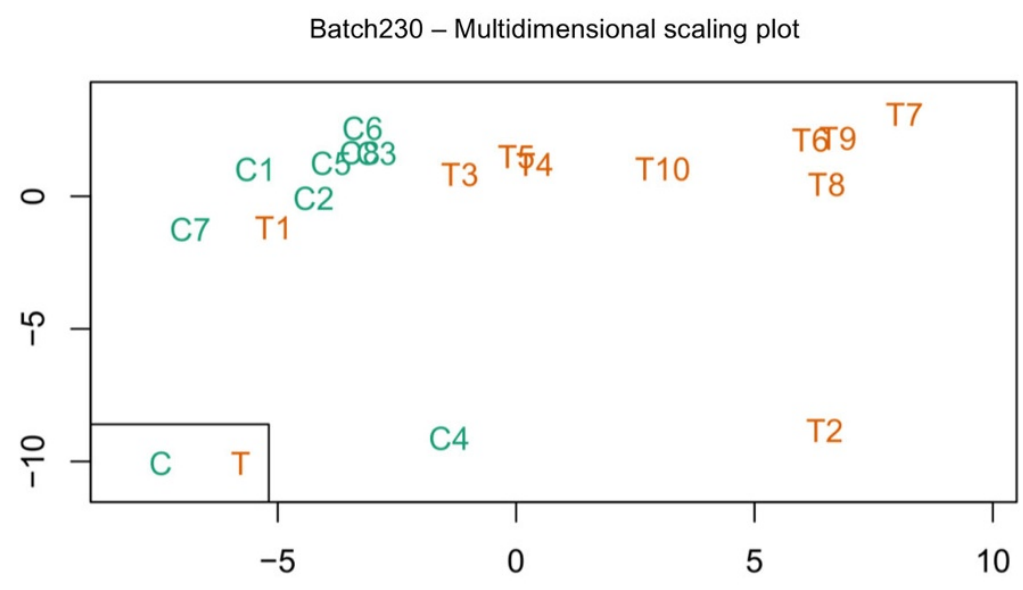

Batch250 - Multidimensional scaling plot

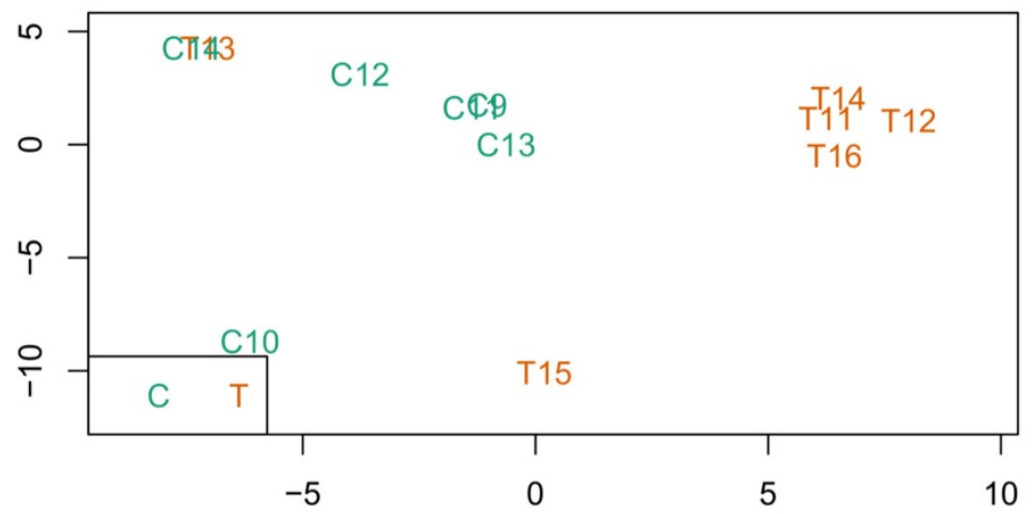

Pooled Dataset - Multidimensional scaling plot

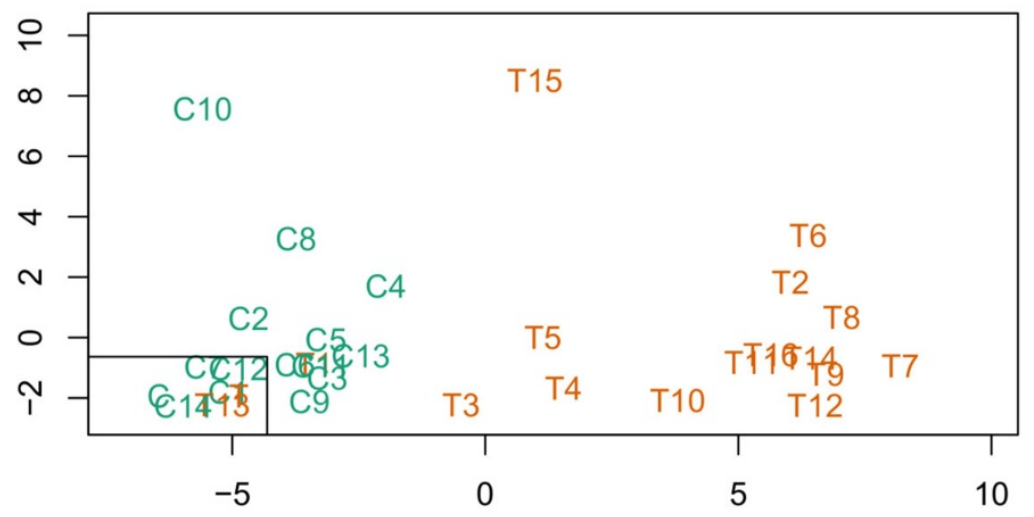

Figure 1 Multidimensional scaling plots for batch230, batch250 and the pooled dataset. Visualisation of the similarity of the normalized methylation samples based on top 1000 most variable probes among all samples in Batch230, Batch250 and the pooled dataset. Label " $\mathrm{C}$ " refers to Control samples (coloured in green), Label "T" refers to Tumour samples (coloured in orange). The expected was to see control and tumour samples discretely. When looked at the plots, there is one tumour sample (T1) for Batch230 and one tumour sample (T13) for Batch250 which are observed closer to the control groups. When looked at the pooled data, although two tumour samples (T13 and T1) are seen as nested with control samples, there is more discrete difference observed between Tumour and Control samples. 

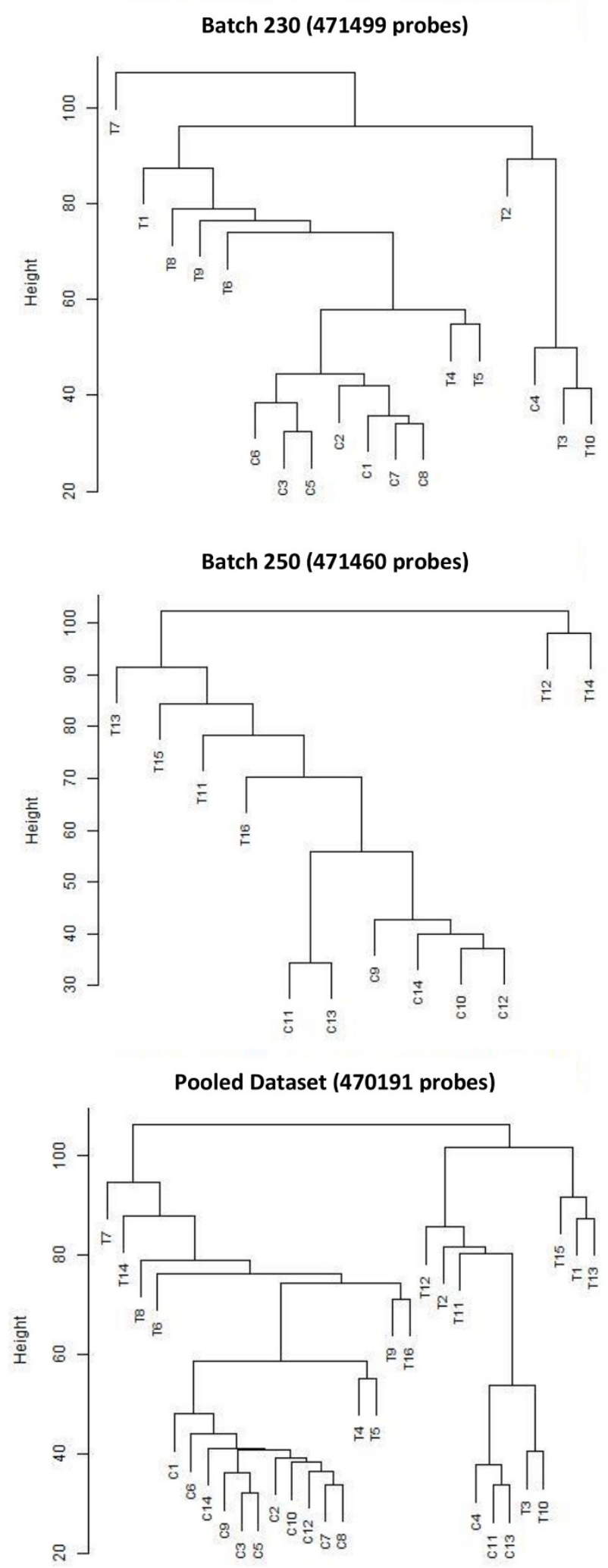

Figure 2 Clustering images for each dataset in our analysis. An alternative to Multidimensional Scaling Plots to visualise the similarity of samples based on all probes using hierarchical clustering. Label " $\mathrm{C}$ " refers to Control samples, Label "T" refers to Tumour samples. The expected was to see control and tumour samples discretely. When looked at the plots, control samples were discretely separated from tumour samples in the pooled dataset. 
of measuring methylation and expression levels in genes, leading to an increase in the significance corresponding to each gene.

After BMIQ normalization, magnitude of batch effects are assessed and corrected using the ComBat normalization method, which is an empirical Bayes based method to correct for technical variation related to the slide [41]. After pre-processing, analysis for Copy Number Aberrations (CNA) and segmentation of methylation variable positions (MVPs) into biologically relevant differentially methylated regions (DMRs) was conducted using the "champ.MVP" function of CHAMP package. In order to have better knowledge about false positive results, Benjamini-Hochberg calculation [42] is applied for all p-values.

\section{RNA sequencing analysis}

RNA sequencing analysis for both batches are conducted using edgeR [43] which is available as a Bioconductor [44] package. It was not possible to download raw sequencing data from TCGA Server, hence quality control, pre-processing, mapping and counting procedures were carried out by the providers of the data [6]. We have worked on counting data and applied EdgeR for detection of differential expression between tumour and control samples, which benefits from empirical Bayes estimation and tests based on the negative binomial distribution [43]. Similar to the methylation analysis, Benjamini-Hochberg correction [42] is conducted for all p-values.

\section{Combining significance values}

For each gene, expression and methylation significances (Benjamini-Hochberg false discovery rates) are combined using survcomp package [45] which is a $\mathrm{R}$ [46] package that provides functions to assess and to compare the performance of risk prediction models.. In more detail, Fisher's weighted Z-method is applied while merging expression and methylation data.

$$
Z_{w}=\frac{w_{X} \frac{\sqrt{n_{X}} \bar{X}}{\widehat{S}_{X}}+w_{Y} \frac{\sqrt{n_{Y}} \bar{Y}}{\widehat{S}_{Y}}}{\sqrt{w_{X}^{2}+w_{Y}^{2}}}
$$

As suggested by Zaykin et al. [47] weights are assigned as square root $\mathrm{N}$, where $\mathrm{N}=$ sample sizes. Functional enrichment results obtained from separate batches are integrated in a similar fashion (Dataset option C for each analysis model).

HumanMethylation450k chip informs about methylation in 450,000 different regions, whereas RNA Sequencing is not region-specific, hence it informs about genes instead of specific regions leading to discrepancy between methylation and expression. As an alternative to individual differential expression and differential methylation results we have merged the two by simply combining the significance values corresponding to each gene. However, regarding the methylation data, there was more than one differentially methylated region falling into the borders of same gene which was causing discrepancy in the data. In our analysis, we have selected the region with the most significant methylation change for each gene. Hence although there were a total of 98366 significantly altered regions for the pooled dataset, after filtering the regions which fall into the same gene, there were a total of 4530 affected unique genes at the end.

\section{Functional enrichment}

Functional analysis for each data set is conducted via PANOGA Functional Enrichment tool [48]. PANOGA incorporates protein-protein interaction information while extracting significant pathways. It helps to identify disease related genes and devise functionally essential KEGG pathways through the identification of genes within the pathways.

PANOGA analysis for results of ten different analysis models were conducted with the help of Cytoscape [49]. At Cytoscape, we have benefitted from JactiveModules package [50] and while using JactiveModules "Number of Modules" was set as 1000 and overlap threshold was set as 0.5 .

However, before giving gene lists as an input to PANOGA we have noticed that some of the genes observed in methylation results were not observed in expression results. For example, PLEC1 gene. As there was no expression information regarding PLEC1 gene, we have excluded that gene from the analysis hence there were a total of 452 genes filtered out in a similar way.

At our analysis, in order to understand the biological distribution of our genes, Gene Ontology (GO) [51] analysis is conducted using ConsensusPathDB functional annotation tool [52]. We have used the option of "overrepresentation analysis" and queried our gene list against Gene Ontology Level 4: Biological Process database with the p-value cut-off of 0.01 . While interpreting the results of ConsensusPathDB, we have searched for 20 most important annotation clusters that were defined by DAVID functional enrichment clustering [53]. Moreover, we have conducted KEGG functional analysis for each term to understand the association between the genes inside of GO terms and the cancer state.

Particularly for our case, significant alteration at posttranslational modification and regulation of transcription pathways were of higher importance as they possess the potential of affecting many biological processes. In order to find out the genes with critical effects, we have searched for transcription factors in TFCat database [54]. 


\section{Analysis performance measure}

In order to evaluate different analysis strategies, we have extracted the list of thyroid cancer-related pathways and genes from previous thyroid cancer researches. For each data and significance merging strategy, our main performance measure was to observe thyroid related pathways in top 20 rankings.

On the other hand, for the purpose of understanding whether combining expression and methylation information results in better significance values for thyroid-cancer associated genes, we have compared significances of differential expression, differential methylation and combination of expression and methylation for Batch 230, Batch 250 and the Pooled dataset. At these tables, we have also included the information of methylation level change for all cases, which is taken as difference in Beta-value corresponding to each gene between two experiment conditions.

\section{Methylation change threshold analysis}

With the aim of comparing the effects of putting various threshold levels for methylation change, a custom script (will be made available upon request) was written which computes inverse correlation between expression and methylation for all regions in the dataset. We have only included the regions having differential methylation and differential expression significance (FDR) below 0.1, which was picked not to be too stringent.

Simply, if methylation of a certain gene is upregulated and expression of the same gene is downregulated, that gene is counted as "inversely correlated". Same is applied for vice versa and as a next step, the ratio between number of inversely correlated genes and total number of genes are calculated for all datasets; in our case Batch230, Batch250 and the pooled dataset.

Lastly, the difference in ratio between above and below varying thresholds in the range of 0.05 (5\%) and 0.5 $(50 \%)$ are computed in order to find out the optimal threshold which favours inverse correlation. This way, for example if the threshold is set at $25 \%$; number of regions with methylation change bigger than $25 \%$ and number of regions with methylation change less than $25 \%$ are compared considering the inverse correlation between expression and methylation at that certain gene. Inverse correlation gains corresponding to each dataset is linearly added together and the threshold with highest overall inverse correlation gain was picked as the best-performer.

\section{Results}

\section{Methylation analysis}

While exploring differentially methylated regions, we have only included the regions having a False Discovery Rate (FDR) lesser than 0.01. As a result, we had a list of 1807 significant differentially methylated regions in
1310 different genes for Batch230 and 946 differentially methylated regions in 730 different genes for Batch250. When both batches were pooled together, we were able to obtain 9333 differentially methylated regions in 4729 different genes.

\section{RNA sequencing analysis}

Likewise, in RNA Sequencing analysis we have only included genes with False Discovery Rate (FDR) lesser than 0.01. As a result of the analysis, there were 2610 differentially expressed genes for Batch230 and there were 1482 differentially expressed genes for Batch250. When normalized expression values of Batch 230 and Batch 250 were pooled together (Pooled dataset), we were able to obtain 4790 differentially expressed genes. (Additional File 1).

\section{Methylation threshold analysis}

In order to test whether setting a valid threshold for methylation change yields enhanced functional enrichment results, an analysis is done for varying thresholds between $0.05(5 \%)$ and 0.5 (50\%) focusing on inverse correlation between expression and methylation. In both Batch230 and Batch250, genes with methylation change larger than $35 \%$ yielded highest ratio $(69.23 \%$, 66.45\% respectively) of inverse correlation with expression. In the pooled dataset on the other hand, setting $40 \%$ methylation change threshold enabled us to reach highest inverse correlation ratio (69.00\%) (Figure 3).

Optimal threshold would be the one that maximizes the difference between ratios above and below of a certain threshold. Although genes having more than $40 \%$ methylation change may be informative about the disease state, setting a $40 \%$ threshold may not be beneficial for finding the optimal results. At our analysis, highest gain of inverse correlation ratio $(29.77 \%)$ was obtained by using the threshold of 0.15 (15\%) (Figure 4).

\section{Functional enrichment analysis}

Ten different analysis models and their short summaries are shown in Table 1. Results regarding first four models are represented in Table 2 and next four models in Table 3. For each of these categories we have set four different result reporting options; only Batch230 results, only Batch250 results, combination of individual batch results (Pathways combined dataset) and Batch230 +Batch250 (Pooled) dataset results. In the pooled dataset as threshold of $40 \%$ yielded highest ratio of inversely correlated genes, we have also made comparison between thresholds of $40 \%$ and $15 \%$ (Table 4). As a result, setting a methylation change threshold of $15 \%$ clearly outperformed setting a threshold of $40 \%$. Moreover, we have compared the effects of inverse and positive correlation and whether which model informs more about the disease 


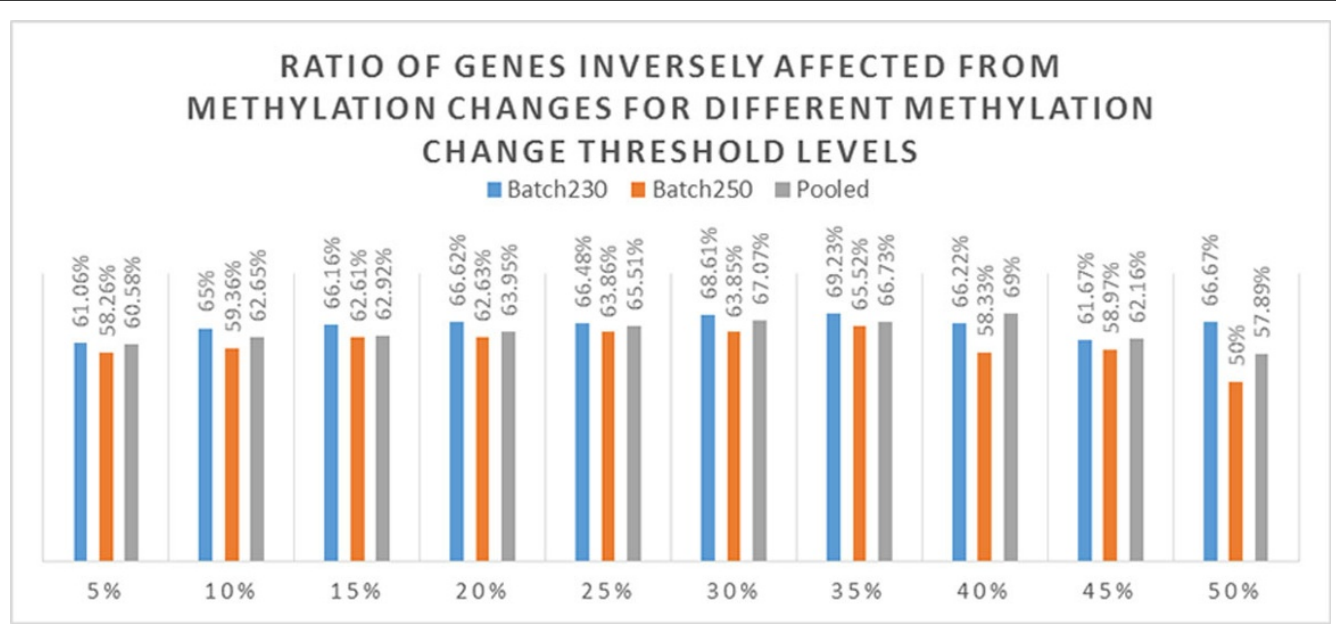

Figure 3 Ratio of genes inversely affected from methylation changes for different methylation change threshold levels. Figure showing ratio of inversely affected genomic regions to total number of affected genomic regions with differential methylation (FDR $<0.01)$ for different methylation change threshold values. Results contain analysis for Batch230, Batch250 and pooled dataset separately. For both Batch230 and Batch250 highest ratio of inverse correlation between methylation and expression is reached with the threshold $35 \%$. For the pooled dataset on the other hand, threshold level of $40 \%$ have highest ratio of inversely affected regions.

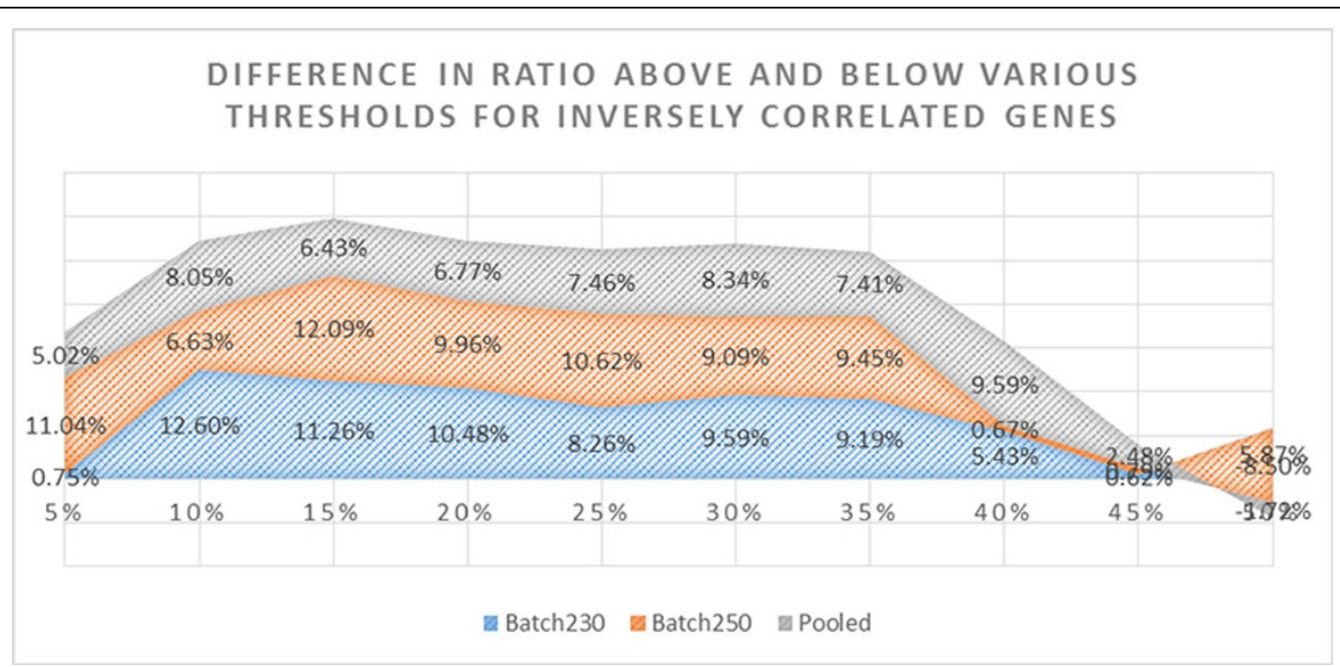

Figure 4 Difference in ratio above and below various thresholds for inversely correlated genes. Figure showing the difference in ratio of inversely correlated genomic regions (methylation $\uparrow$ expression $\downarrow$ and vice versa) above and below varying thresholds. Only regions having differential methylation FDR<0.01 are included. Results contain analysis for Batch230, Batch250 and pooled dataset separately. Considering all three datasets, best performing threshold with highest difference between above and below threshold is $15 \%$. Hence, including threshold of $15 \%$ methylation level change in the analysis may improve the knowledge of disease aetiology.

state (Table 5). When only inverse correlated genes were taken, we have observed 9 pathways in top 20 rankings (Model 8) and when only positively correlated genes were taken (Model 9), we have observed 8 pathways in top 20 rankings. On the other hand, when no filter applied and all genes above the $15 \%$ threshold were taken, we were able to reach the optimal analysis model with 12 pathways in top 20 (Model 7).
Overall, Model 7 was superior to other models at finding thyroid cancer related pathways in top 20 functional enrichment rankings. From this reason, identification of important transcription factors and more detailed functional enrichment analysis using ConsensusPathDB are conducted for the genes in Model 7 (Additional File 2 \& Additional File 3). 
Table 1 Analysis models and their short descriptions.

\begin{tabular}{|c|c|}
\hline $\begin{array}{l}\text { Analysis } \\
\text { Models }\end{array}$ & Model Descriptions (FDR<0.01 for all models) \\
\hline Model 1 & Only differentially expressed genes \\
\hline Model 2 & Only differentially methylated regions \\
\hline Model 3 & Differentially expressed and differentially methylated genes \\
\hline Model 4 & Significant genes when methylation and expression significances combined \\
\hline Model 5 & Genes with more than $15 \%$ methylation change and inversely correlated with expression \\
\hline Model 6 & Genes with more than $15 \%$ methylation change \\
\hline Model 7 & $\begin{array}{c}\text { Significant genes with methylation level change more than } 15 \% \text { and obtained after combining methylation and expression } \\
\text { significance values }\end{array}$ \\
\hline Model 8 & $\begin{array}{c}\text { Significant genes with methylation level change more than 15\%, inversely correlated with expression and obtained after combining } \\
\text { methylation and expression significance values }\end{array}$ \\
\hline Model 9 & $\begin{array}{l}\text { Significant genes with methylation level change more than 15\%, positively correlated with expression and obtained after } \\
\text { combining methylation and expression significance values }\end{array}$ \\
\hline Model 10 & $\begin{array}{c}\text { Significant genes with methylation level change more than } 40 \% \text { and obtained after combining methylation and expression } \\
\text { significance values }\end{array}$ \\
\hline
\end{tabular}

Short summary of each analysis model. For the search of finding the optimal analysis strategy, we have applied 10 different analysis models on different data selection options.

Table 2 Rankings of functional enrichment results - Part 1.

\begin{tabular}{|c|c|c|c|c|c|c|c|c|c|c|c|c|c|c|c|c|}
\hline \multirow[b]{2}{*}{ KEGG TERMs } & \multicolumn{4}{|c|}{$\begin{array}{c}\text { Model } 1 \\
\text { (Differential } \\
\text { Expression FDR<0.01) }\end{array}$} & \multicolumn{4}{|c|}{$\begin{array}{c}\text { Model } 2 \\
\text { (Differential } \\
\text { Methylation } \\
\text { FDR<0.01) }\end{array}$} & \multicolumn{4}{|c|}{$\begin{array}{c}\text { Model } 3 \\
\text { (Both Diff. Meth and Diff. } \\
\text { Expressed FDR<0.01) }\end{array}$} & \multicolumn{4}{|c|}{$\begin{array}{c}\text { Model } 4 \\
\text { (Meth, Expr. Significances } \\
\text { Combined FDR<0.01) }\end{array}$} \\
\hline & A & B & $\mathrm{C}$ & D & A & B & C & D & A & B & $\mathrm{C}$ & D & A & B & $\mathrm{C}$ & D \\
\hline MAPK Signalling & 6 & 7 & 4 & 1 & 10 & 7 & 7 & 17 & 7 & - & 12 & 13 & 17 & 8 & 9 & 8 \\
\hline ECM Receptor & 5 & 5 & 3 & 8 & 26 & - & 52 & 8 & 8 & - & 13 & 1 & 6 & 1 & 3 & 5 \\
\hline ErbB Signalling & 13 & 28 & 20 & 45 & 28 & 1 & 6 & 28 & 14 & - & 20 & 43 & 20 & 22 & 20 & 7 \\
\hline NF-KB Signalling & 32 & 11 & 17 & 85 & 11 & 40 & 18 & 24 & 29 & - & 33 & 47 & 71 & 33 & 46 & 17 \\
\hline Wnt- $\beta$-Catenin Signalling & 51 & 25 & 35 & 73 & 14 & 27 & 16 & 13 & - & - & - & 35 & 86 & 46 & 60 & 28 \\
\hline$\underline{\text { VEGF Signalling }}$ & 46 & 47 & 47 & 105 & 42 & 13 & 23 & 85 & 36 & - & 42 & - & 85 & 84 & 82 & 56 \\
\hline Thyroid Cancer & 30 & 52 & 34 & 66 & 55 & 42 & 43 & - & 12 & 4 & 4 & 65 & 88 & 65 & 74 & 69 \\
\hline Adherens Junction & 34 & 16 & 19 & 24 & 21 & 19 & 20 & 1 & 34 & 5 & 16 & 9 & 21 & 19 & 15 & 9 \\
\hline p53 Signalling & 11 & 18 & 11 & 15 & 68 & - & 77 & 59 & 11 & - & 18 & 23 & 34 & 16 & 22 & 30 \\
\hline TGF-beta Signalling & 3 & 62 & 12 & 5 & 18 & 6 & 12 & 23 & - & 1 & 5 & 5 & 28 & 29 & 29 & 19 \\
\hline Notch Signalling & 60 & 58 & 60 & 57 & 93 & 18 & 42 & 6 & - & - & - & 29 & 59 & 9 & 25 & 13 \\
\hline GnRH Signalling & 61 & 27 & 42 & 26 & 32 & 24 & 24 & 40 & 31 & - & 38 & 26 & 73 & 41 & 54 & 68 \\
\hline Neurotrophin Signalling & 16 & 9 & 8 & 14 & 8 & 4 & 3 & 30 & 5 & - & 10 & 24 & 12 & 5 & 6 & 15 \\
\hline Focal Adhesion & 8 & 1 & 2 & 7 & 1 & 2 & 1 & 2 & 3 & - & 3 & 2 & 7 & 2 & 2 & 3 \\
\hline Transcr. Misregulation & 42 & 21 & 29 & 65 & 13 & - & 40 & - & - & - & - & 37 & 31 & 23 & 28 & 34 \\
\hline Apoptosis & 17 & 19 & 16 & 10 & 12 & - & 39 & 20 & 15 & - & 21 & 16 & 29 & 35 & 31 & 6 \\
\hline Pathways in Cancer & 1 & 2 & 1 & 3 & 2 & 3 & 2 & 16 & 1 & - & 1 & 3 & 1 & 2 & 1 & 2 \\
\hline Toll-like receptor signalling pathway & 14 & 57 & 24 & 32 & 67 & - & 76 & 60 & 28 & - & 32 & - & 102 & 85 & 92 & 43 \\
\hline Pentose-phosphate pathway & 91 & 70 & 80 & 88 & - & 43 & 99 & 88 & - & - & - & 81 & 112 & 87 & 101 & 85 \\
\hline
\end{tabular}

Rankings of previously identified thyroid-cancer associated pathways in PANOGA functional enrichment results. For each analysis strategy four different results are shown in order to understand differences between different data selection strategies; A) Batch230 Results B) Batch250 Results C) Functional Enrichment Results of different Batches combined D) Batch230+Batch250 (Pooled) results. Model 1 represents, genes with differential expression FDR $<0.01$, Model 2 represents, genes with differential methylation FDR $<0.01$, Model 3 represents, genes having both differential expression and differential methylation FDR $<0.01$, Model 4 represents, genes that have FDR $<0.01$ after significance values of methylation and expression are combined. 
Table 3 Rankings of functional enrichment results - Part 2.

\begin{tabular}{|c|c|c|c|c|c|c|c|c|c|c|c|c|c|c|c|c|}
\hline \multirow[b]{2}{*}{ KEGG TERMs } & \multicolumn{4}{|c|}{$\begin{array}{c}\text { Model } 5 \\
(>15 \% \text { Methylation } \\
\text { Change and Inversely } \\
\text { Correlated) }\end{array}$} & \multicolumn{4}{|c|}{$\begin{array}{l}\text { Model } 6 \\
(>15 \% \text {. } \\
\text { Methylation } \\
\text { Change) }\end{array}$} & \multicolumn{4}{|c|}{$\begin{array}{c}\text { Model } 7 \\
\text { (>15\% Methylation } \\
\text { Change, Significances } \\
\text { Combined) }\end{array}$} & \multicolumn{4}{|c|}{$\begin{array}{c}\text { Model } 8 \\
\text { (>15\% Methylation Change, } \\
\text { Inverse Correlated, } \\
\text { Significances Combined) }\end{array}$} \\
\hline & A & B & $\mathrm{C}$ & D & A & B & $C$ & D & A & B & $C$ & D & A & B & $C$ & D \\
\hline MAPK Signalling & - & - & - & 45 & 16 & 3 & 2 & 2 & 29 & 4 & 8 & 6 & - & - & - & 59 \\
\hline ECM Receptor & 14 & - & 28 & 6 & 8 & - & 35 & 3 & 3 & 10 & 3 & 3 & 18 & - & 34 & 7 \\
\hline ErbB Signalling & - & 15 & 13 & 5 & 26 & 6 & 7 & 7 & 28 & 8 & 13 & 10 & 31 & 3 & 4 & 4 \\
\hline NF-KB Signalling & 22 & - & 35 & 29 & 18 & - & 41 & 31 & 20 & - & 39 & 22 & 5 & - & 19 & 11 \\
\hline Wnt $\beta$-Catenin Signalling & 21 & - & 34 & 72 & 64 & 28 & 40 & 46 & 51 & - & 62 & 72 & - & - & - & - \\
\hline VEGF Signalling & 25 & 24 & 17 & 51 & 44 & 34 & 36 & 37 & 50 & 30 & 33 & 30 & 34 & 21 & 17 & 60 \\
\hline Thyroid Cancer & 28 & 14 & 15 & 88 & 32 & 27 & 22 & 106 & 39 & 20 & 22 & 45 & 28 & 17 & 13 & 65 \\
\hline Adherens Junction & 9 & 8 & 5 & 7 & 25 & 24 & 15 & 6 & 26 & 7 & 9 & 14 & 8 & - & 24 & 10 \\
\hline p53 Signalling & - & - & - & 26 & - & - & - & 80 & 40 & - & 50 & 54 & - & - & - & 25 \\
\hline TGF-beta Signalling & - & - & - & 12 & 41 & 32 & 32 & 9 & 10 & 3 & 4 & 13 & - & - & - & - \\
\hline Notch Signalling & 5 & 9 & 2 & 49 & - & 4 & 26 & 24 & 54 & 18 & 28 & 12 & - & 22 & 50 & 55 \\
\hline GnRH Signalling & - & 6 & 23 & 21 & 19 & 33 & 21 & 40 & - & 41 & 78 & 56 & 2 & - & 8 & 37 \\
\hline Neurotrophin Signalling & 7 & 2 & 3 & 15 & 15 & 14 & 8 & 12 & 13 & 13 & 7 & 17 & 20 & - & 36 & 21 \\
\hline Focal Adhesion & 4 & - & 16 & 1 & 3 & 17 & 4 & 1 & 1 & 6 & 2 & 2 & 7 & - & 23 & 2 \\
\hline Transcr. Misregulation & - & - & - & 40 & 30 & - & 48 & 77 & 58 & - & 68 & 51 & - & - & - & 65 \\
\hline Apoptosis & 2 & - & 7 & 8 & 20 & - & 42 & 20 & 6 & - & 27 & 4 & 25 & - & 38 & 1 \\
\hline Pathways in Cancer & 3 & - & 8 & 3 & 1 & 1 & 1 & 8 & 2 & 1 & 1 & 1 & 3 & - & 11 & 3 \\
\hline Toll-like receptor signalling pathway & - & - & - & 75 & - & - & - & - & - & - & - & 8 & - & - & - & 5 \\
\hline Pentose-phosphate pathway & 18 & 12 & 10 & 25 & - & 30 & 64 & - & 34 & 31 & 29 & 18 & 4 & - & 14 & 17 \\
\hline
\end{tabular}

Rankings of previously identified thyroid-cancer associated pathways in PANOGA functional enrichment results - Part2. For each analysis strategy four different results are obtained in order to understand differences between different data selection strategies; A) Batch230 Results B) Batch250 Results C) Functional Enrichment Results of different Batches combined D) Batch230+Batch250 (Pooled) results. Model 5 represents, genes having more than 15\% methylation change and are inversely correlated with expression values, Model 6 represents genes having more than 15\% methylation change, Model 7 represents genes having more than $15 \%$ methylation change and having FDR $<0.01$ after significance values of methylation and expression are combined and finally Model 8 represents, genes having more than $15 \%$ methylation change, inversely correlated with expression values and having $F D R<0.01$ after significance values of methylation and expression are combined.

Table 4 Ranking comparison for $\mathbf{1 5 \%}$ threshold level; between positive correlation, inverse correlation and all together.

\section{Model 7}

(>15\% Methylation Change Significances Combined)
Model 8

(>15\% Methylation Change, Inverse Correlated,Significances Combined)
Model 9

(>15\% Methylation Change, Positively Correlated,Significances Combined)

\begin{tabular}{lccc}
\hline KEGG TERMs & Pooled Dataset & Pooled Dataset & Pooled Dataset \\
\hline MAPK Signalling & $\mathbf{6}$ & 59 & $\mathbf{7}$ \\
\hline ECM Receptor & $\mathbf{3}$ & $\mathbf{7}$ & $\mathbf{4}$ \\
\hline ErbB Signalling & $\mathbf{1 0}$ & $\mathbf{4}$ & $\mathbf{5}$ \\
\hline NF-KB Signalling & 22 & $\mathbf{1 1}$ & - \\
\hline $\begin{array}{l}\text { Wnt- } \beta \text {-Catenin } \\
\text { Signalling }\end{array}$ & 72 & & - \\
\hline VEGF Signalling & 30 & 60 & 53 \\
\hline Thyroid Cancer & 45 & 65 & 27 \\
\hline Adherens Junction & $\mathbf{1 4}$ & $\mathbf{1 0}$ & $\mathbf{1 1}$ \\
\hline p53 Signalling & 54 & 25 & - \\
\hline TGF-beta Signalling & $\mathbf{1 3}$ & - & 42 \\
\hline Notch Signalling & $\mathbf{1 2}$ & 55 & 49 \\
\hline GnRH Signalling & 56 & 37 & 50
\end{tabular}


Table 4 Ranking comparison for $\mathbf{1 5 \%}$ threshold level; between positive correlation, inverse correlation and all together. (Continued)

\begin{tabular}{|c|c|c|c|}
\hline $\begin{array}{l}\text { Neurotrophin } \\
\text { Signalling }\end{array}$ & 17 & 21 & 6 \\
\hline Focal Adhesion & 2 & 2 & 1 \\
\hline $\begin{array}{l}\text { Transcr. } \\
\text { Misregulation }\end{array}$ & 51 & 65 & - \\
\hline Apoptosis & 4 & 1 & - \\
\hline Pathways in Cancer & 1 & 3 & 3 \\
\hline $\begin{array}{l}\text { Toll-like receptor } \\
\text { signalling pathway }\end{array}$ & 8 & 5 & - \\
\hline $\begin{array}{l}\text { Pentose-phosphate } \\
\text { pathway }\end{array}$ & 18 & 17 & 15 \\
\hline
\end{tabular}

Table 5 Ranking comparison between thresholds of $15 \%$ and $40 \%$ in the pooled dataset.

\begin{tabular}{|c|c|c|}
\hline & $\begin{array}{c}\text { Model } 7 \\
(>15 \% \text { Methylation Change, Significances } \\
\text { Combined) }\end{array}$ & $\begin{array}{c}\text { Model } 10 \\
\text { (>40\% Methylation Change, Significances } \\
\text { Combined) }\end{array}$ \\
\hline KEGG TERMs & Pooled Dataset & Pooled Dataset \\
\hline MAPK Signalling & 6 & - \\
\hline ECM Receptor & 3 & 2 \\
\hline ErbB Signalling & 10 & 10 \\
\hline NF-KB Signalling & 22 & - \\
\hline Wnt- $\beta$-Catenin Signalling & 72 & - \\
\hline VEGF Signalling & 30 & 24 \\
\hline Thyroid Cancer & 45 & - \\
\hline Adherens Junction & 14 & 13 \\
\hline p53 Signalling & 54 & - \\
\hline TGF-beta Signalling & 13 & - \\
\hline Notch Signalling & 12 & - \\
\hline GnRH Signalling & 56 & 15 \\
\hline Neurotrophin Signalling & 17 & 9 \\
\hline Focal Adhesion & 2 & - \\
\hline Transcr. Misregulation & 51 & - \\
\hline Apoptosis & 4 & 1 \\
\hline Pathways in Cancer & 1 & - \\
\hline $\begin{array}{l}\text { Toll-like receptor signalling } \\
\text { pathway }\end{array}$ & 8 & - \\
\hline Pentose-phosphate pathway & 18 & - \\
\hline
\end{tabular}

\section{Thyroid cancer - associated genes}

We have investigated thyroid cancer-associated genes with respect to their methylation and expression significances in our datasets (Tables $6,7,8$ ). Out of 25 thyroid-cancer associated genes retrieved from previous researches, for
Batch230 there were a total of 6 differentially methylated and 13 differentially expressed genes whereas for Batch250 there were only two differentially methylated and nine differentially expressed genes with $\mathrm{FDR}<0.01$. On the other hand, we observed a decent increase in the numbers of 
Table 6 Methylation, expression analysis of Batch230 focusing only on thyroid-cancer associated genes.

\begin{tabular}{|c|c|c|c|c|}
\hline & & & Batch230 & \\
\hline & DMR(FDR) & DE (FDR) & FDRs Combined & Methylation Change (percentage) \\
\hline RAP1GAP & $9.85 E-04$ & $4.42 \mathrm{E}-10$ & $1.28 \mathrm{E}-11$ & $-15.75 \%$ \\
\hline TIMP3 & - & - & - & $-28.98 \%$ \\
\hline DAPK & $2.61 \mathrm{E}-03$ & $2.38 \mathrm{E}-06$ & $1.23 \mathrm{E}-07$ & $24.97 \%$ \\
\hline SLC5A8 & - & - & $1.03 \mathrm{E}-03$ & $-3.96 \%$ \\
\hline RARB & - & $7.41 \mathrm{E}-03$ & $2.67 \mathrm{E}-03$ & $-3.22 \%$ \\
\hline TSHR & $2.98 \mathrm{E}-03$ & - & 7.10E-03 & $-9.23 \%$ \\
\hline RASSF6 & $2.59 \mathrm{E}-04$ & - & $1.54 \mathrm{E}-03$ & $-37.42 \%$ \\
\hline CDKN2A & - & $6.15 \mathrm{E}-05$ & $1.22 \mathrm{E}-04$ & $3.38 \%$ \\
\hline $\mathrm{MLH1}$ & - & - & - & $-1.34 \%$ \\
\hline FN1 & - & 1.86E-09 & 1.27E-09 & $-33.47 \%$ \\
\hline FOXE1 & - & - & - & $1.17 \%$ \\
\hline $\mathrm{HGF}$ & - & - & - & $-14.98 \%$ \\
\hline KRT19 & - & $4.26 \mathrm{E}-11$ & $1.64 \mathrm{E}-10$ & $-33.47 \%$ \\
\hline LGALS3 & $8.55 \mathrm{E}-03$ & $1.27 \mathrm{E}-13$ & $3.85 \mathrm{E}-14$ & $-11.78 \%$ \\
\hline MET & - & $1.13 \mathrm{E}-17$ & 7.35E-18 & $-46.44 \%$ \\
\hline RET & - & $1.22 \mathrm{E}-03$ & 4.33E-04 & $-18.49 \%$ \\
\hline KISS1R & - & 2.84E-05 & 3.77E-05 & $-4.81 \%$ \\
\hline ADAMTS5 & - & $3.53 \mathrm{E}-03$ & $8.71 \mathrm{E}-04$ & $27.62 \%$ \\
\hline HOXB4 & - & - & - & $-3.01 \%$ \\
\hline$\overline{T C L 1 B}$ & $3.50 \mathrm{E}-03$ & - & - & $-35.18 \%$ \\
\hline $\mathrm{NOTCH} 4$ & - & - & $9.04 \mathrm{E}-03$ & $-12.10 \%$ \\
\hline RASSF1 & - & - & - & $16.56 \%$ \\
\hline PPARG & - & 3.04E-03 & $1.21 \mathrm{E}-03$ & $-2.92 \%$ \\
\hline ALK & - & $3.27 \mathrm{E}-09$ & $9.25 \mathrm{E}-10$ & $-2.57 \%$ \\
\hline NTRK3 & - & - & - & $-2.15 \%$ \\
\hline
\end{tabular}

Batch230 Results showing Differential Methylation (DMR), Differential Expression (DE), Combination of Differential Methylation and Differential Expression Significances (FDRs Combined) and Methylation Change in \%. Only the values with Differential Expression and Differential Methylation Significances below 0.01 are shown on the table. FDR $>0.01$ are shown as blank. Moreover, methylation change $>15 \%$ are shown as bold. Combining methylation and expression values greatly improves detecting thyroid-associated-genes as significantly altered.

thyroid cancer-associated genes for the pooled dataset where 16 of the genes were found as differentially methylated and 19 as differentially expressed.

When significance values of differential methylation and differential expression were combined for each gene, we were able to capture two additional genes (SLC5A8 and NOTCH4) for Batch230 and one additional gene (RAP1GAP) for Batch250. Upon performing the same analysis for the pooled dataset, we observed 18 differentially altered genes, which was the highest compared to the previous dataset options. The results for the pooled dataset covered all of the genes that were captured on individual batch results, therefore besides combining significance values, pooling, i.e. expanding the dataset, aids at capturing disease-related genes with higher ratio.

\section{Discussion}

For the purpose of understanding the interplay between expression and methylation in thyroid cancer, we have conducted comparisons between four data and ten analysis strategies with respect to the observance rate of thyroid related pathways in the functional enrichment results (Tables 2, 3, 4, 5). Moreover, we have also conducted a threshold analysis to understand whether setting a methylation change threshold improves the outcome of the experiment.

\section{Methylation threshold analysis}

In order to identify the benefits of setting a methylation level threshold, we have conducted a threshold analysis for various threshold levels by calculating the inverse correlation ratio between methylation and expression. When only inverse correlation ratios above different thresholds were looked at, best performing threshold was 35\% for both Batch230 and Batch250 and 40\% for the pooled dataset (Figure 3). However, the reason behind setting a threshold is to witness a concrete difference between above and below thresholds. In this sense, optimal threshold would be the one that maximizes the difference between ratio above and below of a certain threshold. 
Table 7 Methylation, expression analysis of Batch250 focusing only on thyroid-cancer associated gene.

\begin{tabular}{|c|c|c|c|c|}
\hline & & & Batch250 & \\
\hline & DMR(FDR) & DE (FDR) & FDRs Combined & Methylation Change (percentage) \\
\hline RAP1GAP & - & - & $8.31 \mathrm{E}-03$ & $-18.04 \%$ \\
\hline TIMP3 & - & - & - & $-36.24 \%$ \\
\hline DAPK & - & 4.38E-06 & $2.60 \mathrm{E}-06$ & $-23.55 \%$ \\
\hline SLC5A8 & - & - & - & $-11.37 \%$ \\
\hline RARB & - & $9.34 \mathrm{E}-04$ & 5.75E-04 & $-23.60 \%$ \\
\hline TSHR & - & - & - & $-17.94 \%$ \\
\hline RASSF6 & - & - & - & $-14.54 \%$ \\
\hline CDKN2A & - & $1.58 \mathrm{E}-07$ & $1.65 \mathrm{E}-06$ & $14.95 \%$ \\
\hline $\mathrm{MLH1}$ & - & - & - & $-18.74 \%$ \\
\hline FN1 & - & $6.59 \mathrm{E}-10$ & $3.45 \mathrm{E}-10$ & $-39.00 \%$ \\
\hline FOXE1 & - & - & - & $2.18 \%$ \\
\hline $\mathrm{HGF}$ & - & - & - & $-11.01 \%$ \\
\hline KRT19 & - & 9.45E-09 & 1.17E-08 & $-27.31 \%$ \\
\hline LGALS3 & - & $2.58 \mathrm{E}-07$ & $1.21 \mathrm{E}-07$ & $-2.92 \%$ \\
\hline MET & - & 1.10E-09 & 2.25E-09 & $-44.72 \%$ \\
\hline RET & - & - & - & $-12.35 \%$ \\
\hline KISS1R & - & 1.64E-04 & 4.23E-04 & $-1.33 \%$ \\
\hline ADAMTS5 & - & - & - & $30.39 \%$ \\
\hline HOXB4 & - & - & - & $-4.06 \%$ \\
\hline$\overline{T C L 1 B}$ & 8.97E-04 & - & 7.54E-04 & $-37.49 \%$ \\
\hline $\mathrm{NOTCH} 4$ & - & - & - & $-22.75 \%$ \\
\hline RASSF1 & $5.14 \mathrm{E}-03$ & - & - & $20.21 \%$ \\
\hline PPARG & - & - & - & $7.98 \%$ \\
\hline ALK & - & 1.05E-03 & 8.55E-04 & $-19.68 \%$ \\
\hline NTRK3 & - & - & - & $-4.02 \%$ \\
\hline
\end{tabular}

Batch250 Results showing Differential Methylation (DMR), Differential Expression (DE), Combination of Differential Methylation and Differential Expression Significances (FDRs Combined) and Methylation Change in \%. Only the values with Differential Expression and Differential Methylation Significances below 0.01 are shown on the table. FDR $>0.01$ are shown as blank. Moreover, methylation change $>15 \%$ are shown as bold. Combining methylation and expression values greatly improves detecting thyroid-associated-genes as significantly altered.

When investigating the total inverse correlation gain for all three datasets, best performing threshold level was found at "15\%" with $29.77 \%$ correlation gain where improvement in inverse correlation between change in methylation level and expression reached its highest value (Figure 4).

Consequently, when $15 \%$ methylation change threshold was added to Model 4, which previously possessed maximum number of thyroid-cancer associated pathways in top20 functional enrichment rankings, we were able to reach the optimal analysis strategy with 12 thyroid-cancer associated pathways in top 20 rankings (Model 7) (2, 3, 4, 5). Similarly, when Model 2 and Model 6 were compared to each other, addition of 15\% methylation change threshold improved the functional enrichment results by additionally identifying ErbB signalling, TGF-beta signalling and Neurotrophin signalling pathways in top 20 rankings. Thus, it can be argued that the genes with more than $15 \%$ methylation change may be the core reason behind changes in these pathways, which were all associated with thyroid-cancer in previous works.

Moreover, we have also compared functional enrichment results between Model 7, 15\% methylation threshold and Model 10, 40\% methylation threshold, which did not have the highest correlation gain but had the highest inverse correlation percentage in the pooled dataset. As a result, setting 15\% threshold level clearly outperformed threshold of $40 \%$ (Table 4), implying that the information of a "gain of inverse correlation" above and below the threshold is more important than "overall inverse correlation" ratio above the threshold.

\section{Combining methylation and expression data}

Due to the reason that methylation and gene expression have different roles in the development of thyroid cancer, 
Table 8 Methylation, expression analysis of pooled dataset focusing only on thyroid-cancer associated genes.

\begin{tabular}{|c|c|c|c|c|}
\hline & \multicolumn{4}{|c|}{ Pooled Dataset } \\
\hline & DMR(FDR) & DE (FDR) & FDRs Combined & Methylation Change (percentage) \\
\hline RAP1GAP & $1.29 \mathrm{E}-05$ & $4.42 \mathrm{E}-10$ & $1.93 \mathrm{E}-13$ & $-32.37 \%$ \\
\hline TIMP3 & - & $1.46 \mathrm{E}-03$ & - & $-31.69 \%$ \\
\hline DAPK & $2.14 \mathrm{E}-04$ & $1.26 \mathrm{E}-11$ & $3.35 \mathrm{E}-12$ & $24.69 \%$ \\
\hline SLC5A8 & - & 4.80E-04 & 1.99E-04 & $-11.61 \%$ \\
\hline RARB & $7.43 \mathrm{E}-03$ & $6.77 \mathrm{E}-07$ & $1.01 \mathrm{E}-07$ & $-17.92 \%$ \\
\hline TSHR & $6.58 \mathrm{E}-06$ & $1.05 \mathrm{E}-07$ & 8.96E-06 & $-18.12 \%$ \\
\hline RASSF6 & - & $1.05 \mathrm{E}-07$ & $2.31 \mathrm{E}-08$ & $3.85 \%$ \\
\hline CDKN2A & - & $1.57 \mathrm{E}-11$ & $4.87 \mathrm{E}-11$ & $2.92 \%$ \\
\hline MLH1 & - & - & - & $-1.10 \%$ \\
\hline FN1 & $7.00 \mathrm{E}-04$ & $3.78 \mathrm{E}-16$ & $1.16 \mathrm{E}-17$ & $-39.43 \%$ \\
\hline FOXE1 & - & - & - & $1.00 \%$ \\
\hline HGF & - & 7.65E-03 & - & $-1.54 \%$ \\
\hline KRT19 & $2.36 \mathrm{E}-03$ & $2.83 \mathrm{E}-18$ & 3.17E-19 & $-9.87 \%$ \\
\hline LGALS3 & $9.21 \mathrm{E}-05$ & $1.46 \mathrm{E}-19$ & $7.22 \mathrm{E}-22$ & $-9.98 \%$ \\
\hline MET & 1.09E-04 & $1.99 \mathrm{E}-26$ & $1.50 \mathrm{E}-28$ & $-45.69 \%$ \\
\hline RET & $3.08 \mathrm{E}-03$ & $1.01 \mathrm{E}-04$ & 4.96E-06 & $-15.86 \%$ \\
\hline KISS1R & $1.08 \mathrm{E}-03$ & $5.98 \mathrm{E}-11$ & $2.02 \mathrm{E}-12$ & $-4.12 \%$ \\
\hline ADAMTS5 & 7.80E-05 & - & 8.94E-03 & $28.55 \%$ \\
\hline HOXB4 & 1.07E-03 & - & 7.07E-03 & $-3.21 \%$ \\
\hline TCL1B & $5.29 \mathrm{E}-03$ & - & 1.55E-06 & $-35.67 \%$ \\
\hline $\mathrm{NOTCH} 4$ & $6.85 \mathrm{E}-03$ & 4.37E-04 & 4.10E-05 & $-13.05 \%$ \\
\hline RASSF1 & $1.62 \mathrm{E}-03$ & - & $5.08 \mathrm{E}-03$ & $19.06 \%$ \\
\hline PPARG & - & $1.41 \mathrm{E}-05$ & 7.76E-06 & $-2.22 \%$ \\
\hline ALK & 4.69E-04 & $3.79 \mathrm{E}-13$ & $6.63 E-15$ & $9.44 \%$ \\
\hline NTRK3 & - & 4.74E-03 & 4.15E-03 & $-1.44 \%$ \\
\hline
\end{tabular}

Pooled dataset results showing Differential Methylation (DMR), Differential Expression (DE), Combination of Differential Methylation and Differential Expression Significances (FDRs Combined) and Methylation Change in \%. Only the values with Differential Expression and Differential Methylation Significances below 0.01 are shown on the table. FDR $>0.01$ are shown as blank. Moreover, methylation change $>15 \%$ are shown as bold. Combining methylation and expression values greatly improves detecting thyroid-associated-genes as significantly altered.

combining significance values obtained from methylation and expression studies leads to a better detection of thyroid-related genes (Tables 6, 7, 8). To exemplify, for Batch230, SLC5A8 gene was not detected as significantly expressed or significantly methylated. However when the significances of expression and methylation were combined, we observed SLC5A8 as significantly altered with false discovery rate of 0.001 . Similar cases were also observed for Batch250 and pooled dataset, hence combining methylation and gene expression information on pooled data enabled us to obtain highest ratio (21 out of 25) of detecting thyroid-cancer associated genes as significantly altered.

Moreover, for the purpose of understanding the reflection of combining methylation and expression significances on functional enrichment results, we have compared Model 6 (>15\% methylation change) with Model 7 (>15\% methylation change and methylation, expression significances combined) and Model 4 (Only methylation, expression significances combined) with Model 1 (Only differential expression) and Model 2 (Only differential methylation).

Considering the pooled dataset, for Model 6, we have observed 9 thyroid-cancer associated pathways in top20 functional enrichment results whereas for Model 7, which is the same dataset with only methylation and expression significances were combined, we have detected 12 thyroid-cancer associated pathways in top20 functional enrichment results. Similarly, for Model 1 there were 7 and for Model 2 there were 8 thyroid-cancer associated pathways in top20 functional enrichment results. When expression and methylation significances were combined instead of treated separately, we were able to observe 11 important pathways in top 20 functional enrichment results (Model 4). Moreover, there were various pathways that were not 
captured at all in Model 1 and 2, which were only captured when the significances of expression and methylation were combined. For example; in Batch250 differential methylation functional enrichment results (Model 2, B dataset), p53 signalling pathway was not listed as significant at all, with Bonferroni Score above 0.01 . When methylation and expression significances were combined (Model 4, B dataset), p53 signalling pathway was observed at 16th rank with Bonferroni Score 1.51E-12. Similar improvement was also observed among Model 5 and Model 8, as combining significances led to an improved performance with additional detection of toll-like receptor pathway in top 10 rankings.

Consequently, incorporating methylation and expression information together not only improved detection rate of disease-specific genes but it also increased the rankings of disease-specific pathways in functional enrichment results.

Overall, when the data was pooled, methylation, expression significances were combined and only genes with more than $15 \%$ methylation change were selected, best performing results were reached with 12 pathways in top20 functional enrichment results (Table 2, 3, 4, 5) namely; MAPK signalling, Extracellular matrix receptor, ErbB signalling, TGF-beta signalling, Notch signalling, Neurotrophin signalling, Apoptosis, Focal adhesion, Pathways in cancer, Toll-like receptor signalling, Pentose-phospate and Adherens junction pathways.

\section{Testing on an independent dataset}

In addition to the supporting articles from the literature, for the purpose of proving the generalizability and efficiency of our proposed framework, we have applied the same procedures described above on another independent dataset with 30 samples retrieved from thyroid cancer experiments in TCGA. To achieve that, firstly we have calculated the methylation threshold value with "maximum inverse correlation gain", which was also $15 \%$ for the test dataset and secondly, we have combined methylation and expression significances by using Fisher's weighted Z-method. As a result, compared to our training dataset results, we were able to obtain similar pathways in similar rankings in the test dataset, hence there were 11 thyroid cancer-associated pathways in top 20 functional enrichment rankings (Table 9). These findings also support that our approach can be applied to different, independent cancer datasets, which may aid at detecting important pathways for other cancer types as well.

\section{Disease aetiology}

Although there may be other mechanisms at play leading to the thyroid cancer state, in this work we have mainly investigated pathways which were mainly influenced by expression changes highly correlated with methylation changes. While searching for the optimal model, several common pathways were observed at different rankings in almost all of the models, reassuring that methylation change may disturb certain pathways that might be involved in thyroid cancer aetiology. When focusing only on differential methylation results, we have observed significant changes in important pathways such as MAPK Signalling, Wnt- $\beta$-catenin Signalling, Notch signalling, Apoptosis and TGF-beta signalling pathways. Besides the pathways that were directly affected by methylation, other secondary molecular mechanisms were also triggered, such as Transcriptional misregulation, Thyroid cancer and p53 signalling pathways, which were only captured by expression experiments. Specifically when pooled data results which possess more than $40 \%$ methylation change were being investigated (Additional File 4), we observed significant changes in Apoptosis, Extracellular matrix, ErbB, VEGF, GnRH and Neurotrophin signalling pathways. Thus, it is more probable that the core reason behind major changes in these pathways may be due to high methylation level change between disease and normal state (Table 4).

In our analysis, optimal analysis strategy which yielded maximum number of thyroid-cancer associated pathways in top rankings was found to be Model 7. When the functional enrichment results of the best-performing analysis model was investigated in detail, all of the top20 ranked pathways on the list could be associated with thyroid cancer (Additional File 2). In addition to the thyroid-cancer related pathways that were extracted from literature at the beginning, Endocytosis [55], Glutamate [56], Proteasome [57], Gluconeogenesis and glycolysis [58] pathways are found as linked to thyroid cancer in previous works about thyroid cancer.

Furthermore, when the details of 2826 genes that have $>15 \%$ methylation change were explored, some of the GO: Biological Process terms with high significance were: regulation of signal transduction, cell differentiation, phosphate containing metabolic process, morphogenesis and neuron development. For each annotation term, we have performed KEGG functional analysis to examine the association with the cancer state (Table 10). Almost all of the terms were found to be associated with "Pathways in Cancer" which was also supported by the recent literature works [16,37,59-66].

Moreover, since post-translational modification and regulation of transcription pathways are critical for cancer diagnosis and therapy $[67,68]$, we have searched for transcription factors in TFCat database [54] and as a result, 207 out of 2826 genes (7.32\%) were annotated as transcription factors (S2 Table) and 245 out of 2826 genes $(8.66 \%)$ were annotated as being involved in post- 
Table 9 Validating the proposed framework with a new dataset.

\begin{tabular}{|c|c|c|}
\hline & $\begin{array}{c}\text { Training Dataset } \\
\text { (>15\% Methylation Change, Significances } \\
\text { Combined) }\end{array}$ & $\begin{array}{c}\text { Test Dataset } \\
(>15 \% \text { Methylation Change, Significances } \\
\text { Combined) }\end{array}$ \\
\hline KEGG TERMs & Pooled & Pooled \\
\hline MAPK Signalling & 6 & 11 \\
\hline ECM Receptor & 3 & 1 \\
\hline ErbB Signalling & 10 & 16 \\
\hline NF-KB Signalling & 22 & 25 \\
\hline Wnt- $\beta$-Catenin Signalling & 72 & 80 \\
\hline VEGF Signalling & 30 & 69 \\
\hline Thyroid Cancer & 45 & 68 \\
\hline Adherens Junction & 14 & 19 \\
\hline p53 Signalling & 54 & 17 \\
\hline TGF-beta Signalling & 13 & 7 \\
\hline Notch Signalling & 12 & 83 \\
\hline GnRH Signalling & 56 & 15 \\
\hline Neurotrophin Signalling & 17 & 12 \\
\hline Focal Adhesion & 2 & 2 \\
\hline Transcr. Misregulation & 51 & - \\
\hline Apoptosis & 4 & 20 \\
\hline Pathways in Cancer & 1 & 4 \\
\hline $\begin{array}{l}\text { Toll-like receptor signalling } \\
\text { pathway }\end{array}$ & 8 & - \\
\hline Pentose-phosphate pathway & 18 & 75 \\
\hline
\end{tabular}

Comparison between the training and test dataset. For the training dataset, optimal results were obtained using Model 7. When the same analysis procedure of training dataset is applied to the test dataset (30 samples), similar results were obtained. There were $12 \mathrm{KEGG}$ functional annotation terms for the training dataset whereas this number was 11 for the test dataset, which shows that our proposed framework is also applicable to independent datasets.

Table 10 GO - Biological process functional annotation results for Model 7.

\begin{tabular}{|c|c|c|c|c|}
\hline GO: Biological Process Terms & $\begin{array}{l}\text { No. of genes that overlap } \\
\text { with our list }\end{array}$ & $\begin{array}{l}\text { Associated } \mathrm{q}- \\
\text { value }\end{array}$ & $\begin{array}{l}\text { No. of genes in cancer } \\
\text { pathway }\end{array}$ & $\begin{array}{c}\text { Association with cancer } \\
\text { pathway }\end{array}$ \\
\hline Regulation of Signal Transduction & $540(21.5 \%)$ & $1.54 \mathrm{E}-29$ & 56 & $2.06 \mathrm{E}-15$ \\
\hline $\begin{array}{l}\text { Cellular Development Process, Cell } \\
\text { Differentiation }\end{array}$ & $633(19.2 \%)$ & $2.16 \mathrm{E}-21$ & 74 & $4.02 \mathrm{E}-23$ \\
\hline $\begin{array}{l}\text { Phosphate Containing Compound } \\
\text { Metabolic Process }\end{array}$ & $653(19.1 \%)$ & $2.16 \mathrm{E}-21$ & 59 & $2.35 \mathrm{E}-14$ \\
\hline $\begin{array}{l}\text { Anatomical Structure Formation, } \\
\text { Morphogenesis }\end{array}$ & $271(22.7 \%)$ & $8.04 \mathrm{E}-17$ & 34 & $1.72 \mathrm{E}-11$ \\
\hline Neuron Development & $229(23.9 \%)$ & $8.47 \mathrm{E}-17$ & 29 & $1.57 \mathrm{E}-09$ \\
\hline Actin Cytoskeleton Organization & $142(27.6 \%)$ & $1.53 \mathrm{E}-15$ & 13 & $1.46 \mathrm{E}-03$ \\
\hline Regulation of Catalytic Activity & $411(19.8 \%)$ & $3.30 \mathrm{E}-15$ & 48 & $5.03 E-15$ \\
\hline Circulatory System Development & $199(23.3 \%)$ & $1.67 \mathrm{E}-13$ & 40 & 1.45E-19 \\
\hline Cell Junction Assembly & $70(33.8 \%)$ & $3.87 \mathrm{E}-12$ & 10 & $3.12 \mathrm{E}-04$ \\
\hline Vasculature Development & $139(24.9 \%)$ & $1.28 \mathrm{E}-11$ & 28 & $1.27 \mathrm{E}-13$ \\
\hline Regulation of Adhesion & $137(24.7 \%)$ & $2.71 \mathrm{E}-11$ & 25 & $1.46 \mathrm{E}-11$ \\
\hline Regulation of Programmed Cell Death & $339(19.3 \%)$ & $5.69 \mathrm{E}-11$ & 48 & $2.25 \mathrm{E}-17$ \\
\hline Protein Kinase Activity & $180(22.0 \%)$ & $4.18 \mathrm{E}-10$ & 30 & $3.16 \mathrm{E}-15$ \\
\hline Response to External Stimulus & $142(23.1 \%)$ & $1.83 \mathrm{E}-09$ & 20 & 4.95E-07 \\
\hline Epithelium Development & $214(20.5 \%)$ & 4.47E-09 & 46 & $1.07 \mathrm{E}-25$ \\
\hline Response to Growth Factor & $151(22.1 \%)$ & 9.85E-09 & 35 & $5.21 \mathrm{E}-19$ \\
\hline
\end{tabular}


Table $10 \mathrm{GO}$ - Biological process functional annotation results for Model 7. (Continued)

\begin{tabular}{lllll}
\hline Protein Modification Process & $526(17.0 \%)$ & $5.44 \mathrm{E}-08$ & 57 & $6.96 \mathrm{E}-17$ \\
\hline Regulation of Developmental Process & $190(19.6 \%)$ & $1.19 \mathrm{E}-06$ & 36 & $7.49 \mathrm{E}-17$ \\
\hline Regulation of Cell Growth & $71(21.5 \%)$ & $4.62 \mathrm{E}-05$ & 9 & $3.88 \mathrm{E}-03$ \\
\hline Mesonephros Development & $27(26.0 \%)$ & $3.82 \mathrm{E}-04$ & 12 & $2.08 \mathrm{E}-10$ \\
\hline
\end{tabular}

Biological Process annotation table for significantly altered genes in Model 7 obtained using ConsensusPathDB. Out of 340 GO: Biological Process terms with qvalue $<0.01$, information of 20 important terms are reported. For each annotation term in the list, we have conducted KEGG Pathway Analysis. Almost all of the terms were significantly associated with "Pathways in Cancer".

translational modification processes with Benjamini significance of "7.98E-05" in ConsensusPathDB analysis. Consequently, these genes may be active at altering other pathways, revealing other mechanisms involved in thyroid cancer.

\section{Conclusion}

Overall, we define a comprehensive analysis strategy for incorporating methylation and expression information, which enables detection of primary and secondary mechanisms associated with the thyroid cancer. As a result of our case study, incorporating methylation and expression information is a viable strategy at detecting disease-related genes and disease-related pathways more efficiently. Moreover, while increasing the number of samples improves the analysis confidence of the experiment, optimal results with respect to disease-related pathways were obtained after setting a valid threshold for change in methylation level, which is defined by considering the inverse correlation gain above and below of a certain threshold. From biological perspective, MAPK signalling, Extracellular matrix, Focal adhesion, ErbB signalling, Apoptosis, TGF-beta signalling, Glutamatergic synapse and Toll-like receptor signalling pathways were found as significantly altered in our analysis, hence these pathways may be the core pathways that are involved in thyroid cancer. Furthermore, significantly altered transcription factors and post-translational modifiers distinguished by our analysis strategy may be crucial at identifying secondary mechanisms lying behind thyroid cancer. We believe that our approach on incorporating methylation and expression data reveals insights of thyroid cancer which cannot be extracted using only methylation or only expression data.

\section{Additional material}

Additional file 1: Gene Expression MA plots of Batch230, Batch250 and Pooled Dataset. Vertical axis represent log ratios between two measurements, which are colored in black and red. Horizontal axis represent mean values of two measurements.

Additional file 2: Panoga Top20 functional enrichment results when methylation and expression significances are combined for the Pooled dataset, and only genes with $>15 \%$ methylation change are selected (Model 7).
Additional file 3: List of transcription factors that have more than $15 \%$ methylation change in pooled dataset.

Additional file 4: Top 20 functional enrichment result for the pooled dataset with genes having $>40 \%$ methylation change.

\section{Competing interests}

The authors declare that they have no competing interests.

\section{Authors' contributions}

$\mathrm{BO}$ and US wrote the article together. US was the advisor in the whole procedure. BO performed all analyses including DNA methylation and RNASeq expression analysis. Both authors have read and approved the manuscript for publication.

\section{Acknowledgements}

We would like to thank National Cancer Institute for The Cancer Genome Atlas (TCGA) for making essential cancer data from different platforms publicly available, Ilknur Melis Durasi for helping at functional enrichment and transcription factor analyses, Burcu Bakir Gungor for providing additional instructions on PANOGA protocol and Vibin Varghese for reviewing the manuscript. Moreover, the project was supported by Republic of Turkey Ministry of Development Infrastructure Grant (no: 2011K120020) and BILGEM - TUBITAK (The Scientific and Technological Research Council of Turkey) (grant no: 100132)

\section{Declarations}

Publication charges for this article have been funded by Acibadem University.

This article has been published as part of BMC Genomics Volume 16 Supplement 12, 2015: Joint 26th Genome Informatics Workshop and 14th International Conference on Bioinformatics: Genomics. The full contents of the supplement are available online at http://www.biomedcentral.com/ bmcgenomics/supplements/16/S12.

\section{Authors' details}

'Biological Sciences and Bioengineering Program, Faculty of Engineering and Natural Sciences, Sabanci University, Istanbul, Turkey. ${ }^{2}$ Advanced Genomics and Bioinformatics Research Center (IGBAM), The Scientific and Technological Research Council of Turkey (TUBITAK), 41470, Gebze, Kocaeli, Turkey. ${ }^{3}$ Department of Biostatistics and Medical Informatics, Faculty of Medicine, Acıbadem University, Ataşehir, Istanbul, 34752, Turkey.

Published: 9 December 2015

\section{References}

1. Xing M: Molecular pathogenesis and mechanisms of thyroid cancer. Nat Rev Cancer 2013, 13(3):184-199.

2. Cohen $Y$, Xing M, Mambo E, Guo Z, Wu G, Trink B, et al: BRAF mutation in papillary thyroid carcinoma. J Natl Cancer Inst 2003, 95(8):625-627.

3. Kikuchi Y, Tsuji E, Yagi K, Matsusaka K, Tsuji S, Kurebayashi J, et al: Aberrantly methylated genes in human papillary thyroid cancer and their association with BRAF/RAS mutation. Front Genet 2013, 4:271.

4. Knauf JA, Fagin JA: Role of MAPK pathway oncoproteins in thyroid cancer pathogenesis and as drug targets. Curr Opin Cell Biol 2009, 21(2):296-303. 
5. Mitsutake N, Miyagashi M, Mitsutake S, Akeno N, Mesa C, Knauf JA: BRAF mediates RET/PTC-induced mitogen-activated protein kinase activation in thyroid cells: functional support for requirement of the RET/PTC-RASBRAF pathway in papillary thyroid carcinogenesis. Endocrinology 2006, 147(2):1014-1019.

6. Cancer Genome Atlas Research Network: Integrated genomic characterization of papillary thyroid carcinoma. Cell 2014, 159(3):676-690.

7. Mohammadi-asl J, Larijani B, Khorgami Z, Tavangar SM, Haghpanah V, Kheirollahi $\mathrm{M}$, et al: Qualitative and quantitative promoter hypermethylation patterns of the P16, TSHR, RASSF1A and RARbeta2 genes in papillary thyroid carcinoma. Med Oncol 2011, 28(4):1123-1128.

8. Hoque $M O, E, W H, M, P, M A$, et al: Quantitative assessment of promoter methylation profiles in thyroid neoplasms. J Clin Endocrinol Metab 2005, 90(7):4011-4018.

9. Xing M, Cohen Y, Mambo E, Tallini G, Udelsman R, Ladenson PW: Early occurrence of RASSF1A hypermethylation and its mutual exclusion with BRAF mutation in thyroid tumorigenesis. Cancer Res 2004, 64(5):1664-1668

10. Rodriguez-Rodero $S$, Fernandez AF, Fernandez-Morera $J$, Castro-Santos $P$, Bayon GF, Ferrero C, et al: DNA methylation signatures identify biologically distinct thyroid cancer subtypes. J Clin Endocrinol Metab 2013, 98(7):2811-2821

11. Cakir M, Grossman AB: Medullary thyroid cancer: molecular biology and novel molecular therapies. Neuroendocrinology 2009, 90(4):323-348.

12. Lu'o'ng KV, Nguyen LT: The role of thiamine in cancer: possible genetic and cellular signaling mechanisms. Cancer Genomics Proteomics 2013, 10(4):169-185.

13. Pisarev MA, Thomasz $L$, Juvenal GJ: Role of transforming growth factor beta in the regulation of thyroid function and growth. Thyroid 2009, 19(8):881-892.

14. Vieira JM, Santos SC, Espandinha C, Correia I, Vag T, Casalou C, et al: Expression of vascular endothelial growth factor (VEGF) and its receptors in thyroid carcinomas of follicular origin: a potential autocrine loop. Eur J Endocrinol 2005, 153(5):701-709.

15. McGregor LM, McCune BK, Graff JR, McDowell PR, Romans KE, Yancopoulos GD, et al: Roles of trk family neurotrophin receptors in medullary thyroid carcinoma development and progression. Proc Nat Acad Sci U S A 1999, 96(8):4540-4545.

16. Owens LV, Xu L, Dent GA, Yang X, Sturge GC, Craven RJ, et al: Focal adhesion kinase as a marker of invasive potential in differentiated human thyroid cancer. Ann Surg Oncol 1996, 3(1):100-105.

17. Yeh MW, Rougier JP, Park JW, Duh QY, Wong M, Werb Z, et al: Differentiated thyroid cancer cell invasion is regulated through epidermal growth factor receptor-dependent activation of matrix metalloproteinase (MMP)-2/gelatinase A. Endocr Relat Cancer 2006 13(4):1173-1183

18. Sastre-Perona A, Santisteban P: Role of the wnt pathway in thyroid cancer. Front Endocrinol (Lausanne) 2012, 3:31.

19. Malaguarnera $R$, Vella $V$, Vigneri $R$, Frasca $F: p 53$ family proteins in thyroid cancer. Endocr Relat Cancer 2007, 14(1):43-60.

20. Yamashita AS, Geraldo MV, Fuziwara CS, Kulcsar MAV, Friguglietti CU, da Costa RB, et al: Notch pathway is activated by MAPK signaling and influences papillary thyroid cancer proliferation. Trans/ Oncol 2013, 6(2):197-205

21. Huang WY, Hsu SD, Huang HY, Sun YM, Chou CH, Weng SL, et al: MethHC: a database of DNA methylation and gene expression in human cancer. Nucleic Acids Res 2014, 43(D1):D856-D861.

22. Lowe SW, Lin AW: Apoptosis in cancer. Carcinogenesis 2000, 21(3):485-495.

23. Shih A, Davis FB, Lin HY, Davies PJ: Resveratrol induces apoptosis in thyroid cancer cell lines via a MAPK- and p53-dependent mechanism. J Clin Endocrinol Metab 2002, 87(3):1223-1232.

24. Jones PA, Baylin SB: The fundamental role of epigenetic events in cancer. Nat Rev Genet 2002, 3(6):415-428.

25. Baylin SB, Ohm JE: Epigenetic gene silencing in cancer - a mechanism for early oncogenic pathway addiction? Nat Rev Cancer 2006, 6(2):107-116.

26. Feinberg AP, Oshimura M, Barrett JC: Epigenetic mechanisms in human disease. Cancer Res 2002, 62(22):6784-6787.

27. Alashwal H, Dosunmu R, Zawia NH: Integration of genome-wide expression and methylation data: relevance to aging and Alzheimer's disease. Neurotoxicology 2012, 33(6):1450-1453.
28. Gervin K, Vigeland MD, Mattingsdal M, Hammero M, Nygard H, Olsen AO, et al: DNA methylation and gene expression changes in monozygotic twins discordant for psoriasis: identification of epigenetically dysregulated genes. PLoS Genet 2012, 8(1):e1002454.

29. Paziewska A, Dabrowska M, Gorya K, Antoniewicz A, Dobruch J, Mikula M, et al: DNA methylation status is more reliable than gene expression at detecting cancer in prostate biopsy. Br J Cancer 2014, 111(4):781-789.

30. Fan S, Zhang $X: C p G$ island methylation pattern in different human tissues and its correlation with gene expression. Biochem Biophys Res Commun 2009, 383(4):421-425.

31. Li M, Balch C, Montgomery JS, Jeong M, Chung JH, Yan P, et al: Integrated analysis of DNA methylation and gene expression reveals specific signaling pathways associated with platinum resistance in ovarian cancer. BMC Med Genomics 2009, 2:34.

32. Taskesen E, Havermans M, van Lom K, Sanders MA, van Norden Y, Bindels E, et al: Two splice-factor mutant leukemia subgroups uncovered at the boundaries of MDS and AML using combined gene expression and DNA-methylation profiling. Blood 2014, 123(21):3327-3335.

33. Kim D, Shin H, Song YS, Kim JH: Synergistic effect of different levels of genomic data for cancer clinical outcome prediction. J Biomed Inform 2012, 45(6):1191-1198.

34. List M, Hauschild AC, Tan Q, Kruse TA, Mollenhauer J, Baumbach J, et al: Classification of breast cancer subtypes by combining gene expression and DNA methylation data. J Integr Bioinform 2014, 11(2):236.

35. Remenyi A, Scholer HR, Wilmanns M: Combinatorial control of gene expression. Nat Struct Mol Biol 2004, 11(9):812-815

36. Bird AP: DNA methylation versus gene expression. J Embryol Exp Morphol 1984, 83 Suppl:31-40.

37. Sherr CJ: Cell cycle control and cancer. Harvey Lect 2000, 96:73-92.

38. Butcher LM, Beck S: Probe Lasso: a novel method to rope in differentially methylated regions with 450K DNA methylation data. Methods 2015, 72:21-28.

39. Du P, Zhang $X$, Huang CC, Jafari N, Kibbe WA, Hou L, et al: Comparison of Beta-value and $M$-value methods for quantifying methylation levels by microarray analysis. BMC Bioinformatics 2010, 11:587

40. Teschendorff AE, Marabita F, Lechner M, Bartlett T, Tegner H, GomezCabrero D, et al: A beta-mixture quantile normalization method for correcting probe design bias in Illumina Infinium $450 \mathrm{k}$ DNA methylation data. Bioinformatics 2013, 29(2):189-196.

41. Johnson WE, Li C, Rabinovic A: Adjusting batch effects in microarray expression data using empirical Bayes methods. Biostatistics 2007, 8(1):118-127.

42. Benjamini YHY, Hochberg Y: Controlling the false discovery rate: a practical and powerful approach to multiple testing. Journal of Royal Statistical Society B 1995, 57(1):289-300.

43. Robinson MD, McCarthy DJ, Smyth GK: edgeR: a Bioconductor package for differential expression analysis of digital gene expression data. Bioinformatics 2010, 26(1):139-140

44. Gentleman RC, Carey VJ, Bates DM, Bolstad B, Dettling M, Dudoit S, et al: Bioconductor: open software development for computational biology and bioinformatics. Genome Biol 2004, 5(10):R80.

45. Schroder MS, Culhane AC, Quackenbush J, Haibe-Kains B: survcomp: an R/ Bioconductor package for performance assessment and comparison of survival models. Bioinformatics 2011, 27(22):3206-3208.

46. R Development Core Team: R: A language and environment for statistical computing. R Foundation for Statistical Computing: Vienna, Austria 2014.

47. Zaykin DV: Optimally weighted Z-test is a powerful method for combining probabilities in meta-analysis. J Evol Biol 2011, 24(8):1836-1841.

48. Bakir-Gungor B, Egemen E, Sezerman OU: PANOGA: a web server for identification of SNP-targeted pathways from genome-wide association study data. Bioinformatics 2014, 30(9):1287-1289.

49. Shannon P, Markiel A, Ozier O, Baliga NS, Wang JT, Ramage D, et al Cytoscape: a software environment for integrated models of biomolecular interaction networks. Genome Res 2003, 13(11):2498-2504.

50. Ideker T, Ozier O, Schwikowski B, Siegel AF: Discovering regulatory and signalling circuits in molecular interaction networks. Bioinformatics 2002, , 18 Suppl 1: S233-S240.

51. Ashburner M, Ball CA, Blake JA, Botstein D, Butler H, Cherry JM, et al: Gene ontology: tool for the unification of biology. The Gene Ontology Consortium. Nat Genet 2000, 25(1):25-29. 
52. Kamburov A, Stelzl U, Lehrach H, Herwig R: The ConsensusPathDB interaction database: 2013 update. Nucleic Acids Res 2013, 41(Database issue):D793-D800

53. Huang da W, Sherman BT, Lempicki RA: Systematic and integrative analysis of large gene lists using DAVID bioinformatics resources. Nat Protoc 2009, 4(1):44-57.

54. Fulton DL, Sundararajan S, Badis G, Hughes TR, Wasserman WW, Roach JC, et al: TFCat: the curated catalog of mouse and human transcription factors. Genome Biol 2009, 10(3):R29.

55. Lanzetti L, Di Fiore PP: Endocytosis and cancer: an 'insider' network with dangerous liaisons. Traffic 2008, 9(12):2011-2021.

56. Rzeski W, Ikonomidou C, Turski L: Glutamate antagonists limit tumor growth. Biochem Pharmacol 2002, 64(8):1195-1200.

57. Conticello C, Adamo L, Giuffrida R, Vicari L, Zeuner A, Eramo A, et al: Proteasome inhibitors synergize with tumor necrosis factor-related apoptosis-induced ligand to induce anaplastic thyroid carcinoma cell death. J Clin Endocrinol Metab 2007, 92(5):1938-1942.

58. Shulman GI, Ladenson PW, Wolfe MH, Ridgway EC, Wolfe RR: Substrate cycling between gluconeogenesis and glycolysis in euthyroid, hypothyroid, and hyperthyroid man. J Clin Invest 1985, 76(2):757-764.

59. Hanahan D, Weinberg RA: The hallmarks of cancer. Cell 2000, 100(1):57-70.

60. Ozcan A, Shen SS, Hamilton C, Anjana K, Coffrey D, Krishnan B, et al: PAX 8 expression in non-neoplastic tissues, primary tumors, and metastatic tumors: a comprehensive immunohistochemical study. Mod Pathol 2011, 24(6):751-764.

61. Saharinen P, Tammela T, Karkkainen MJ, Alitalo K: Lymphatic vasculature: development, molecular regulation and role in tumor metastasis and inflammation. Trends Immunol 2004, 25(7):387-395.

62. Klein I, Ojamaa K: Thyroid hormone and the cardiovascular system. N Engl J Med 2001, 344(7):501-509.

63. Yang J, Weinberg RA: Epithelial-mesenchymal transition: at the crossroads of development and tumor metastasis. Dev Cell 2008, 14(6):818-829.

64. Dvorak HF: Vascular permeability factor/vascular endothelial growth factor: a critical cytokine in tumor angiogenesis and a potential target for diagnosis and therapy. J Clin Oncol 2002, 20(21):4368-4680.

65. Vivanco I, Sawyers CL: The phosphatidylinositol 3-Kinase AKT pathway in human cancer. Nat Rev Cancer 2002, 2(7):489-501.

66. Kouvaraki MA, Shapiro SE, Perrier ND, Cote GJ, Gagel RF, Hoff AO, et al: RET proto-oncogene: a review and update of genotype-phenotype correlations in hereditary medullary thyroid cancer and associated endocrine tumors. Thyroid 2005, 15(6):531-544.

67. Darnell JE Jr: Transcription factors as targets for cancer therapy. Nat Rev Cancer 2002, 2(10):740-749.

68. Krueger KE, Srivastava S: Posttranslational protein modifications: current implications for cancer detection, prevention, and therapeutics. Mol Cell Proteomics 2006, 5(10):1799-1810.

doi:10.1186/1471-2164-16-S12-S7

Cite this article as: Ozer and Sezerman: A novel analysis strategy for integrating methylation and expression data reveals core pathways for thyroid cancer aetiology. BMC Genomics 2015 16(Suppl 12):S7.

\section{Submit your next manuscript to BioMed Central and take full advantage of:}

- Convenient online submission

- Thorough peer review

- No space constraints or color figure charges

- Immediate publication on acceptance

- Inclusion in PubMed, CAS, Scopus and Google Scholar

- Research which is freely available for redistribution 